\title{
EXTENSÃO UNIVERSITÁRIA E MELHORIA DA QUALIDADE DA ALIMENTAÇÃO DA COMUNIDADE DE NAVIRAÍ-MS
}

\author{
Giovanna Lara dos Santos de Oliveira ${ }^{1}$ \\ ORCID: 0000-0003-4651-3680 \\ Pedro Paullo Alves dos Santos ${ }^{1}$ \\ ORCID: 0000-0002-2480-0665 \\ Mariana Manfroi FuZinatto² \\ ORCID: 0000-0002-6678-6654 \\ Silvia BenedeTti ${ }^{2}$ \\ ORCID: 0000-0003-2604-0505
}

\begin{abstract}
Resumo: Esse projeto de extensão foi desenvolvido pelos alunos do curso de Engenharia de Alimentos da UEMS, no município de Naviraí-MS, objetivando a melhoria da qualidade dos alimentos produzidos e comercializados em padarias do município, visando o bem estar e a saúde da comunidade. Nas três padarias participantes foram coletadas informações sobre as condições higiênico-sanitárias da produção e dos manipuladores. A partir dos dados coletados, foram identificados os principais problemas e os alunos puderam elaborar materiais informativos e repassar seu conhecimento aos manipuladores de alimentos, de modo a melhorar a qualidade dos alimentos comercializados no município. A experiência obtida pelos membros do projeto bem como dos estabelecimentos participantes mostrou a importância do Projeto de Extensão voltados para esse público, possibilitando uma imersão de estudos dos alunos para além da sala de aula, além de contribuir com a melhoria da qualidade dos alimentos comercializados no município.
\end{abstract}

Palavras-chave: Saúde coletiva. Higiene. Alimentos. Qualidade.

1 Discentes do curso de Engenharia de Alimentos, Universidade Estadual de Mato Grosso do Sul (UEMS), Naviraí, Mato Grosso do Sul, Brasil. E-mail: pedropaullo2018@gmail.com

2 Docentes do curso de Engenharia de Alimentos, Universidade Estadual de Mato Grosso do Sul (UEMS), Naviraí, Mato Grosso do Sul, Brasil. E-mail: silviabene@gmail.com 


\title{
UNIVERSITY EXTENSION AND IMPROVE- MENT OF THE FOOD QUALITY IN THE NA- VIRAÍ-MS CITY
}

\begin{abstract}
This extension project was developed by students of the UEMS Food Engineering course in the municipality of Naviraí-MS, aiming at improving the quality of food produced and marketed in bakeries of the municipality, aiming at the well-being and health of the community. Information on the hygienic-sanitary conditions tf the production and the manipulators was collected at the three participating bakeries. From the collected data, the main problems were identified and the students were able to elaborate informative materials and transfer their knowledge to the food handlers, in order to improve the quality of the foods commercialized in the municipality. The experience gained by the members of the project and the participating establishments showed the importance of the Extension Project aimed at this audience, allowing students to immerse themselves in studies beyond the classroom, as well as contribute to the improvement of the quality of the foods commercialized in the city. Keywords: Collective health. Hygiene. Foods. Quality.
\end{abstract}

\section{EXTENSIÓN UNIVERSITARIA Y MEJORA DE LA CALIDAD DE LA ALIMENTACIÓN DE LA COMUNIDAD DE NAVIRAÍ-MS}

Resumen: Este proyecto de extensión fue desarrollado por los alumnos del curso de Ingeniería de Alimentos de la UEMS, en el municipio de Naviraí-MS, con el objetivo de mejorar la calidad de los alimentos producidos y comercializados en panaderías del municipio, buscando el bienestar y la salud de la comunidad. En las tres panaderías participantes fueron recolectadas informaciones sobre las condiciones higiénico-sanitarias de la producción y de los manipuladores. A partir de los datos recolectados, se identificaron los principales problemas y los alumnos pudieron elaborar materiales informativos y repasar su conocimiento a los manipuladores de alimentos, para mejorar la calidad de los alimentos comercializados en el municipio. La experiencia obtenida por los miembros del proyecto así como de los establecimientos participantes mostró la importancia del Proyecto de Extensión orientados a ese público, posibilitando una inmersión de estudios de los alumnos más allá del aula, además de contribuir con la mejora de la calidad de los alimentos comercializados en el municipio. Palabras clave: Salud pública. Higiene. Alimentos. Calidad.

Submetido em: 10/12/2018

Aceito em: 20/12/2018 


\section{INTRODUÇÃO}

A história do pão praticamente se confunde com a do homem, sendo que os primeiros pães elaborados por humano tinha como matérias primas o trigo e a água, o qual foi definido como uma variedade de pão rudimentar. Ao decorrer do tempo, as formulações foram modificadas e aperfeiçoadas, mas o pão sempre esteve presente na história da evolução humana. Atualmente, pode-se dizer que o pão é um dos alimentos mais consumidos mundialmente. Nos últimos anos houve um aumento de seu consumo no Brasil, o qual se encontrava em 2018, na décima primeira posição mundial de vendas de pães industrializados em milhões de toneladas, e em décima posição mundial em vendas de bolos industrializados em milhões de toneladas (ABIMAPI, 2018).

No país, há cerca 70 mil padarias, sendo que $96 \%$ delas se classificam como micro e pequenas empresas, contudo este setor representa uma importante fonte de empregos uma vez que geravam, em 2018, mais de 800 mil empregos diretos e 1,8 milhão de forma indireta (ABIP, 2018). Com estes dados estatísticos é evidente que este ramo alimentício deve atender à legislação vigente sobre Boas Práticas para garantir a segurança alimentar e preservar a saúde pública, pois há grande preocupação do consumidor com a qualidade dos alimentos e com os riscos que eles podem acarretar à saúde.

Os produtos de panificação apresentam baixa atividade de água, desta forma oferecem baixo risco de veiculação de doenças, porém as padarias de forma geral vêm produzindo alimentos de confeitaria, como bolos e doces. Assim com a adoção de outras atividades além da panificação, é imprescindível a implantação e cumprimento de estratégias de Boas Práticas de Fabricação (SEBRAE, 2010).

A falta de esclarecimentos entre as pessoas que lidam com os alimentos contribui de forma significativa para a sua contaminação, fazendo necessário adotar, através de capacitações, medidas sanitárias rigorosas na manutenção de um padrão adequado de higiene dos indivíduos que trabalham em serviços de alimentação (ALVES, 2012).

$\mathrm{Na}$ área de alimentação, estudos apontam o manipulador de alimentos como uma variável importante da cadeia produtiva que necessita de controle, pois ele pode interferir diretamente na qualidade sanitária do produto final (PANZA et al., 2008). Cerca de 60\% das enfermidades de origem alimentar causadas por micro-organismos patogênicos têm como responsáveis os 
manipuladores. Esses agentes microbiológicos podem estar presentes na boca, nariz, garganta, mãos e no trato intestinal de humanos. A contaminação ocorre, geralmente, nas etapas de manipulação e preparo dos alimentos (SOUZA, 2006).

É preciso considerar os perigos que os produtos de panificação podem apresentar, tais como perigos físicos que podem compreender fragmentos de vidros e metais presentes na matéria- prima ou incorporados à massa durante o preparo, fragmentos de insetos e roedores, parafusos e peças metálica que podem desprender dos equipamentos; e também perigos biológicos que estão relacionados à contaminação microbiana ocasionada por armazenagem inadequada; e os perigos químicos que compreendem aos resíduos de detergentes, desinfetantes e, principalmente, as mico toxinas, que são toxinas produzidas por fungos ou bolores durante um armazenamento inapropriado (SEBRAE, 2010).

Segundo o Ministério da Saúde, no ano de 2018 foram 503 surtos de DTA (Doenças transmitidas por alimentos) notificados, com 6.803 doentes, 731 hospitalizados e 9 óbitos relacionados. O que demonstra $0,13 \%$ de letalidade. De 2009 a 2018 foram 99 óbitos recorrentes de surtos de DTA. Numerosos surtos de DTA atraem atenção da mídia, e aumentam o interesse dos consumidores que anseiam cada vez mais, por informações que esclareçam a forma de produção do alimento que está sendo ingerido pelos mesmos, evidenciando que se torna cada vez mais necessário fabricar alimentos seguros.

De acordo com a RDC no 216/2004, a fabricação de alimentos pelos estabelecimentos devem contemplar os seguintes requisitos gerais: manutenção higiênico-sanitária dos edifícios, instalações e utensílios, controle da qualidade da água de abastecimento, controle da higiene e saúde dos manipuladores, capacitação profissional, manejo de resíduos, controle e garantia de qualidade do alimento preparado, controle integrado de vetores e pragas urbanas (BRASIL, 2004).

Fica claro, portanto, a grande importância do cumprimento da legislação vigente pertinente às Boas Práticas, para que os estabelecimentos possam fornecer alimentos seguros e de qualidade aos consumidores. Assim é de grande utilidade uma avaliação desses estabelecimentos bem como um estudo sobre o que pode ser feito com base na legislação vigente, verificando possíveis correções e propondo, posteriormente, um material informativo, visto que é de extrema importância a compreensão da legislação por parte dos 
manipuladores para que possam compreender e seguir as Boas Práticas de Fabricação de Alimentos.

O estabelecimento que cumpre as técnicas e mantém os cuidados necessários conseguirá oferecer aos seus clientes uma mercadoria de qualidade, o que implicará em um empreendimento bem sucedido que, por sua vez, é sinônimo de maior lucratividade, não só para o proprietário, mas também para os funcionários, que terão melhores salários e trabalho assegurado.

Além da grande troca de conhecimento entre estudante executante do projeto e as manipuladoras de alimentos, o trabalho consegue promover a produção de um alimento íntegro, seguro, e de melhor qualidade para a comunidade em geral. De acordo Artur (2004), os alimentos são considerados íntegros e seguros quando estão próprios para o consumo humano atendendo aos critérios de não causar infecção ou intoxicação alimentar quando manipulados e preparados de maneira adequada.

\section{METODOLOGIA}

Uma vez submetido e aprovado pela Divisão de Extensão/PROEC da Universidade Estadual de Mato Grosso do Sul no ano de 2016, o projeto de Avaliação das condições higiênico-sanitárias dos estabelecimentos produtores de alimentos do município de Naviraí-MS foi apresentado a estabelecimentos produtores de alimentos dos mais diversos segmentos pelos alunos bolsistas de extensão do curso de Engenharia de Alimentos. Nessa primeira etapa, os estabelecimentos que aceitaram participar do projeto firmaram um compromisso através da assinatura de uma autorização para execução das atividades. Diante disso, foi entregue ao estabelecimento um documento protocolado pela UEMS, juntamente com a apresentação do aluno executante e as ações previstas do projeto.

Após a autorização do estabelecimento para a realização do trabalho, elaborou-se um questionário contendo nove perguntas objetivas e discursivas e aplicou-se aos manipuladores para que eles respondessem, com o intuito de avaliar os seus conhecimentos prévios. Os estabelecimentos participantes foram denominados genericamente como: Padaria A, Padaria B e padaria C.

Para avaliação das condições higiênico-sanitárias dos estabelecimentos, utilizou-se um check-list elaborado com base legal, na Resolução RDC n $^{\circ}$ 275 de 21 de outubro de 2002 (BRASIL, 2002) e na Resolução RDC nº 216 de 
15 de setembro de 2004 (BRASIL, 2005). Foram avaliadas as condições das instalações, edificações, equipamentos, móveis e utensílios a fim de verificar cada item listado. As condições higiênico-sanitárias e o modo operacional de sanitização foram analisados visualmente, e em seguida, percebeu-se a não existência de registros ou quaisquer documentos que provassem a forma e o local em que as mesmas foram feitas. A estrutura interna e externa do estabelecimento foi aferida para visualização do controle de pragas e vetores, sendo este item listado significativo para as futuras ações corretivas. Avaliaram-se as condições higiênicas dos reservatórios de água, bem como tubulações e torneiras.

As matérias-primas utilizadas na produção dos alimentos foram selecionadas dentro dos próprios estabelecimentos que as comercializam. As embalagens são terceirizadas, de boa qualidade e dentro das normas. Após estarem devidamente preparados, os alimentos são dispostos em mostruários para que os clientes tenham fácil visualização e praticidade. Poucos produtos são armazenados, pois apresentam vida útil curta e grande aceitação do público alvo.

Após a observação das atividades de manipulação dos alimentos, foram constatadas algumas falhas operacionais. Iniciou-se, então, a aplicação de medidas corretivas nas não conformidades, através da apresentação dos procedimentos de Boas Práticas de Manipulação de Alimentos, em consonância com a RDC no 216/2004, a fim de garantir a manipulação higiênica dos alimentos preparados.

Oito POPs foram elaborados para atender às necessidades das padarias, com base na RDC n² 216/2004. O POP compreende a descrição detalhada de todas as medidas necessárias para a realização de um procedimento, padronizando a produção de alimento e, consequentemente, tornando-o padronizado e mais seguro para o consumo.

Para encerramento das atividades do projeto, foi ministrada uma palestra intitulada "Boas Práticas de Manipulação de Alimentos" para todos os manipuladores de alimentos dos estabelecimentos que participaram das atividades. Abordou-se a importância das Boas Práticas de Manipulação de Fabricação de Alimentos para a garantia da comercialização e consumo de um alimento seguro. 


\section{RESULTADOS E DISCUSSÃO}

Desde 2016, quando o projeto de extensão de Boas práticas de manipulação de alimentos foi implantado no curso de Engenharia de Alimentos da UEMS- Naviraí, diversos subprojetos foram desenvolvidos pelos alunos bolsistas PIBEX, todos contemplando estabelecimentos que produzem e comercializam alimentos e/ou servem refeições coletivas, como escolas. Desde então, diversos trabalhos já foram apresentados em eventos científicos, sendo até premiados pelo mérito acadêmico e pelos benefícios proporcionados à população com a execução do projeto.

Nesse projeto nas padarias, os resultados das atividades propostas pelos alunos extensionistas foi extremamente positiva, pois puderam contribuir através de seu conhecimento técnico para orientar os manipuladores de alimentos do município e, com isso, melhorar a qualidade e garantir a saúde e bem estar da população ao consumir os alimentos produzidos no município. O Quadro 1 apresenta o questionário aplicado aos manipuladores para identificar o nível de conhecimento dos mesmos sobre as Boas Práticas de Manipulação de Alimentos.

QUADRO 1 - QUESTIONÁRIO APLICADO AOS MANIPULADORES DOS TRÊS ESTABELECIMENTOS AVALIADOS.

\begin{tabular}{|c|c|}
\hline Questão & Descrições das perguntas \\
\hline 1 & Assinale os itens que estão incluídos nas Boas Práticas de Manipulação. \\
\hline 2 & $\begin{array}{l}\text { Com que frequência deve ser higienizada as instalações, os equipamentos, } \\
\text { móveis e utensílios? }\end{array}$ \\
\hline 3 & $\begin{array}{c}\text { Quais são os hábitos que precisam ser evitados durante a manipulação para } \\
\text { proteger os alimentos de contaminação? }\end{array}$ \\
\hline 4 & Assinale o (s) fator (es) que podem provocar doenças de origem alimentar. \\
\hline 5 & $\begin{array}{l}\text { Se o cloro acabar no seu local de trabalho, qual o outro meio de } \\
\text { higienização de utensílios e equipamentos que você poderia utilizar? }\end{array}$ \\
\hline 6 & $\begin{array}{c}\text { Qual a diferença de água tratada e água potável? Quais das duas podem ser } \\
\text { utilizadas na manipulação de alimentos? }\end{array}$ \\
\hline 7 & $\begin{array}{l}\text { Como devem ser rotulados os alimentos preparados ou fracionados, no } \\
\text { local de comercialização e embalados na presença do consumidor? }\end{array}$ \\
\hline 8 & Assinale qual faixa de risco para crescimento de microrganismos. \\
\hline 9 & $\begin{array}{l}\text { Quais são os cuidados que se deve ter no armazenamento para não } \\
\text { comprometer a qualidade e a segurança do alimento? }\end{array}$ \\
\hline
\end{tabular}

A partir das respostas dadas pelos manipuladores, constatou-se que na padaria A obteve-se $100 \%$ de conformidade das respostas com a legislação 
sobre boas práticas na manipulação de alimentos, enquanto nas padarias B e C obteve-se 80 e $44 \%$ de conformidade nas respostas, respectivamente. Esses resultados são provenientes de certa "falta de interesse" por parte do responsável pela padaria $\mathrm{C}$ em investir em treinamentos, já que eles exigem gastos, o que difere bruscamente da Padaria, que por ser franquia investe mais em treinamentos dos funcionários.

O check-list aplicado era composto por 50 itens divididos em 22 blocos. Os índices de não conformidades variaram entre 9 e $71 \%$, conforme pode ser observado na Tabela 1.

TABela 1 - PeRCENTUAis dAS NÃO CONFORMIDADES OBTIDAS NO CHECK-LIST APLICADO NAS PADARIAS.

\begin{tabular}{|c|c|c|c|c|c|c|c|c|c|}
\hline \multirow[t]{2}{*}{ AV } & \multicolumn{3}{|c|}{ Padaria A } & \multicolumn{3}{|c|}{ Padaria B } & \multicolumn{3}{|c|}{ Padaria C } \\
\hline & IV & NC & $\%$ & IV & NC & $\%$ & IV & NC & $\% \mathrm{~V}$ \\
\hline $\begin{array}{c}\text { Instalações e } \\
\text { estrutura }\end{array}$ & 33 & 3 & 9,1 & 33 & 4 & 12,1 & 33 & 16 & 48,5 \\
\hline $\begin{array}{c}\text { Equipamentos, } \\
\text { móveis e } \\
\text { utensílios }\end{array}$ & 10 & 6 & 60,0 & 10 & 2 & 20,0 & 10 & 5 & 50,0 \\
\hline Manipuladores & 7 & 1 & 14,3 & 7 & 5 & 71,4 & 7 & 4 & 57,1 \\
\hline TOTAL & 50 & 10 & 20,0 & 50 & 11 & 22,0 & 50 & 25 & 50,0 \\
\hline
\end{tabular}

AV = ASPECTOS AVALIADOS; IV = ITENS DE VERIFICAÇÃO; NC = NÃO CONFORMIDADES.

Dos três estabelecimentos participantes, dois foram classificados como regulares, apresentando percentuais de conformidades entre 50 e 80 $\%$. Na padaria A haviam falhas em relação à concentração de sanificantes utilizados na limpeza. Também apresentava problemas na organização dos alimentos no armazenamento, com muito desperdício e produtos vencidos devido à falta da utilização do método PEPS (primeiro que entra, primeiro que sai). Entretanto, foram observados poucos problemas na manipulação dos alimentos, o que pode ser explicado pelo fato dos manipuladores já terem participado de treinamentos anteriores sobre boas práticas de higiene na manipulação de alimentos.

Já na padaria $\mathrm{B}$, a grande maioria das falhas foi observada na manipulação e higiene dos manipuladores, que portavam adereços e adornos como brincos, relógio, pulseiras, além de conversarem sobre o alimento que estava 
sendo produzido. Alves et al. (2012) constataram em seu estudo referente aos hábitos dos manipuladores que $88 \%$ dos mesmos não espirraram sobre os alimentos, não tossiram, não cuspiram, e não se coçaram, no entanto o comportamento indesejável mais frequente foi o falar desnecessariamente durante a manipulação dos alimentos.

Castro et al. (2006) observaram, no que diz respeito aos hábitos higiênicos, que $100 \%$ dos manipuladores de um estudo de nove restaurantes analisados não lavavam adequadamente as mãos. Ribeiro et al. (2007) relataram que a lavagem das mãos não era frequente e a contaminação cruzada ocorria através dos próprios manipuladores de alimentos. Verificou-se que a higienização das mãos nas padarias $\mathrm{B}$ e $\mathrm{C}$ também eram inadequadas.

A padaria $C$ foi a que mais apresentou inadequações dentre as avaliadas, com sérios problemas no armazenamento dos alimentos após o preparo, tornando-o uma possível fonte de contaminação para os consumidores. Esse era um estabelecimento familiar, onde não eram obedecidas as exigências técnicas da legislação vigente sobre segurança dos alimentos. Os manipuladores nunca haviam passado por um treinamento, apenas disseram ter recebido instruções para fazer "produtos gostosos". Além disso, observou-se neste estabelecimento que a maioria dos manipuladores dos alimentos ingeria alimentos na área de produção. No estudo realizado por de Alves e colaboradores (2012), observou-se que em $12 \%$ dos estabelecimentos investigados os manipuladores beliscavam ou faziam lanches durante a produção de alimentos e que em $8 \%$ destes lugares, eles experimentavam os alimentos diretamente nas mãos ou com utensílios, mas depois os reutilizavam para mexer os alimentos sem antes realizar a higienização dos mesmos. A contenção destes hábitos é importante, pois reduz os riscos de contaminação sobre os alimentos, visto que os manipuladores representam um dos principais veículos de contaminação (SILVA JÚNIOR, 2008).

De acordo com Goés et al. (2001), a educação e o treinamento periódico dos manipuladores de alimentos são fundamentais para a manutenção da qualidade higiênico sanitária dos produtos alimentícios, já que a maioria das toxi-infecções alimentares está relacionada com a contaminação do alimento pelo manipulador. Os objetivos da adoção de medidas visando à higiene pessoal são para assegurar aos funcionários que estão em contato direto ou indireto com os alimentos, que estes não tenham possibilidades de contaminar os 
produtos, manter um grau apropriado de asseio corporal e comportando-se e atuando de maneira adequada (BRASIL, 2002).

Com relação à elaboração dos POPs, oito foram elaborados: 1)Controle da potabilidade da água; 2) Controle integrado de vetores e pragas urbanas; 3 ) Manejo de resíduos e lixo; 4) Controle da higiene e saúde dos manipuladores; 5) Seleção de fornecedores; 6) Condições de armazenamento; 7) Condições de recebimento, e 8)Exposição de alimentos ao consumidor final.

Esses POPs foram entregue aos funcionários, e em seguida foi aplicado um treinamento rápido para que soubessem buscar informações nos mesmos da forma correta. Sabe-se que o treinamento/capacitação de manipuladores é o procedimento de maior importância para a prevenção de contaminação de alimentos, durante as diferentes etapas de seu preparo, e associando este treinamento com um intenso programa de educação para estes manipuladores, espera-se que se minimizem os riscos, e seja assegurada dentro de limites, a qualidade sanitária dos alimentos produzidos.

A execução desse projeto trouxe benefícios significativos aos estabelecimentos e à comunidade, visto que melhorando a higiene na manipulação dos alimentos, garante-se que os produtos alimentícios comercializados nas padarias sejam seguros e de qualidade a população local.

No encerramento do projeto, foi ministrada uma palestra a todos os manipuladores de alimentos dos estabelecimentos participantes. A palestra foi ministrada por sete alunos do curso de Engenharia de Alimentos de Naviraí, todos participantes desse projeto de extensão, tendo como tema "Boas Práticas de Manipulação de Alimentos", onde foram abordadas informações básicas, desde a forma como se deve limpar uma caixa d'água, até à importância das Boas Práticas de Manipulação de Fabricação de Alimentos para a garantia da comercialização e consumo de um alimento seguro. Além da apresentação oral, ocorreram dinâmicas com a finalidade de envolver os manipuladores presentes, proporcionando trocas de conhecimentos.

\section{CONGLUSÕES}

Com o desenvolvimento do projeto, obteve-se boa aceitação e interação dos manipuladores de alimentos e proprietários dos estabelecimentos nas atividades, os quais solicitavam informações e opinavam sobre as possíveis melhorias no processo, com a finalidade de melhorar as condições higiênicas- sanitárias 
da fabricação, manipulação e qualidade dos alimentos. É notório que as ações corretivas difundiram conhecimento técnico, sobre a qualidade e segurança dos produtos acabados e comercializados nas padarias no município de Naviraí-MS, o que tornou de grande importância a elaboração dos POPs, juntamente com a apresentação da palestra sobre segurança alimentar, higiene e boas práticas.

Os objetivos previstos foram alcançados, sendo que a execução deste projeto foi de grande valia para as padarias participantes. Os manipuladores de alimentos demonstraram todo tempo, anseio por conhecimentos técnicos e métodos que fomentem as boas práticas de fabricação. Portanto, a execução do projeto ocorreu de forma eficiente, resultando na melhoria da qualidade dos alimentos comercializados nas padarias no município.

Ainda que o projeto tenha sido realizado de forma eficiente, os critérios de higiene pessoal e demais conhecimentos das Boas Práticas de Manipulação precisam ser abordados em capacitações para manipuladores de alimentos e supervisionados diariamente nos locais de produção. Estas formações devem ser contínuas e cuidadosamente elaboradas, com atividades teóricas e práticas, a fim de proporcionar o ressignificado do conhecimento e promover mudanças de hábitos nos manipuladores. Assim é possível contribuir favoravelmente para a qualidade higiênica sanitária dos alimentos servidos à população.

A criação e o desenvolvimento desse projeto de extensão vêm comprovando que, além de promover a interação entre os alunos do curso de Engenharia de Alimentos e os produtores/manipuladores de alimentos do município de Naviraí-MS, cria-se um vínculo entre a universidade e a comunidade, fortalecendo a importância da atuação universitária no meio onde está inserida, não só como geradora de conhecimento, mas também de protagonismo social. A promoção do conhecimento adquirido tecnicamente na universidade pode ser usada beneficamente a favor da comunidade, de modo que haja essa promoção do relacionamento entre diferentes áreas de conhecimento a favor do bem comum.

\section{REFERÊNCIAS}

ALVES, E.; GIARETTA, A. G; COSTA, F. M. Higiene pessoal dos manipuladores de alimentos dos shoppings centers da região da grande Florianópolis, Rev. Técnico Científica (IFSC), v. 3, n. 1 ,604-14, 2012. 
ARTUR, P. de O. Aplicação do binômio tempo/temperatura em alimentos. 2004. 57 f. Trabalho de Conclusão de Curso (Especialização)-Universidade de Brasília, Brasília, 2004.

Associação Brasileira das Indústrias de Biscoitos, Massas Alimentícias e Pães \& Bolos Industrializados. Dia Mundial do Pão. São Paulo, SP, 2015. Disponível em: http://www. abimapi.com.br/dia-do-pao.php. Acesso em: 10 Jan. 2017.

Associação Brasileira das Indústrias de Biscoitos, Massas Alimentícias e Pães \& Bolos Industrializados. Estatísticas. São Paulo, SP, 2018. Disponível em: http://www.abimapi. com.br/estatistica-paes-bolos.php. Acesso em: 01 Maio 2019.

Associação Brasileira da Indústria de Panificação e Confeitaria. Indicadores da panificação e confeitaria brasileira 2018. Brasília, DF, 2015. Disponível em: http://www.abip. org.br/site/indicadores-da-panificacao-e-confeitaria-brasileira-2018/. Acesso em: 01 dez. 2018.

BRASIL. Ministério da Saúde. Agência Nacional da Vigilância Sanitária. Resolução RDC $\mathbf{n}^{\circ}$ 216, de 15 de setembro de 2004. Regulamento Técnico de Boas Práticas para Serviços de Alimentação. Brasília, DF.

BRASIL. Resolução (RDC) no. 275, de 21 de outubro de 2002. Diário Oficial (da) República Federativa do Brasil, Brasília, DF, 6 nov. 2002.

CASTRO, F. T. et al. Restaurantes self-services: situação higiênico-sanitária dos shoppings do município do Rio de Janeiro. Revista Universidade Rural, Rio de Janeiro, v. 26, n. 2, p. $87-101,2006$.

GÓES, J.A.W. et al. Capacitação dos manipuladores de alimentos e a qualidade da alimentação servida. Higiene Alimentar. São Paulo, v. 15, n. 82, p. 20-22, 2001.

MINISTÉRIO DA SAÚDE. Surtos de Doenças Transmitidas por Alimentos no Brasil. Fev. 2019. Disponível em: http://portalarquivos2.saude.gov.br/images/pdf/2019/fevereiro/15/Apresenta----o-Surtos-DTA---Fevereiro-2019.pdf. Acesso em: 01 maio 2019.

PANZA,S.G.A; SPONHOLZ, T.K. Manipulador de alimentos, um fator de risco na transmissão de enteropararitoses. Revista Higiene Alimentar. São Paulo, v.22,n.13,p. 42-47, 2008.

SEBRAE. Boas Práticas na Panificação e na Confeitaria- Da produção ao ponto de venda. Brasília, DF, 2010. Disponível em: http://www.abip.org.br/site/wp-content/uploads/2016/01/cartilhafinalizada.pdf. Acesso em: 10 Jan. 2017.

SILVA, J. E. A. Manual de controle higiênico-sanitário em alimentos. 2.ed. São Paulo, SP: Varela, 2008.

SOUZA, L.H.L. A manipulação inadequada dos alimentos: Fator de contaminação. Revista Higiene Alimentar, vol. 20n. 146,p. 32-39, São Paulo, 2006.

RIBEIRO, K. L.; SCHMIDT, V. Caracterização de manipuladores de alimentos em escolas municipais de Viamão, RS. Revista Higiene Alimentar, São Paulo, v. 21, n. 157, p. 58-64, 2007. 